\title{
Peer review to prevent, manage, and learn from catastrophic complications in perioperative medicine
}

\author{
Ophélie Loup, ${ }^{1}$ Charles J. Fox, ${ }^{2}$ Ghali E. Ghali, ${ }^{3}$ Elyse M. Cornett, ${ }^{2}$ and Markus M. Luedi ${ }^{3}$ \\ ${ }^{1}$ Bern University Hospital Inselspital, Department of Cardiac Surgery, University of Bern, Bern, Switzerland \\ 2 Louisiana State University Health Sciences Center, Department of Anaesthesiology, Shreveport LA, USA \\ ${ }^{3}$ Louisiana State University Health Sciences Center, Department of Oral and Maxillofacial Surgery, Shreveport LA, USA \\ ${ }^{4}$ Bern University Hospital Inselspital, Department of Anaesthesiology and Pain Medicine, University of Bern, Bern, Switzerland
}

\section{Background and purpose}

Audits, checklists, guidelines, and practice advisories considerably improved safety in the perioperative setting. Yet, given the reality of multi-generational and multicultural workforces and discoveries in management sciences, the community is only just about to recognise the importance of peer review in perioperative medicine.

While the concept of feedback has been institutionalized across various settings over the past decades, peer review take place on a different level in organizational hierarchy and depends heavily on individual and departmental culture. We aimed to shed light on this crucial activity to prevent, manage and learn from catastrophic complications.

\begin{tabular}{|c|c|}
\hline HR Tool & Setting \\
\hline $\begin{array}{l}\text { Traditional (end of year) } \\
\text { performance evaluation }\end{array}$ & $\begin{array}{l}\text { Top down tool for evaluating an employee according } \\
\text { to job descriptions, expected performance goals } \\
\text { and defined measures and goals considering } \\
\text { various dimensions. Easy to objectify but difficult } \\
\text { to apply for non standard settings. }\end{array}$ \\
\hline $\begin{array}{l}\text { Feedback } \\
\text { A conversation on "a view to } \\
\text { narrowing the gap between } \\
\text { observed and desired } \\
\text { performance"2 }\end{array}$ & $\begin{array}{l}\text { Established and well recognized teaching tool in } \\
\text { clinical training to reinforce good and improve } \\
\text { poor performance. } \\
\text { Depending on the cultural setting and the mindsets } \\
\text { of the protagonists involved, feedback might } \\
\text { be weakened by confusion between content of } \\
\text { the feedback and relationship between the parties. }\end{array}$ \\
\hline $360^{\circ}$ evaluation & $\begin{array}{l}\text { Open or anonymous feedback from inferiors, superiors } \\
\text { and colleagues at same hierarchy level considering } \\
\text { various dimensions. }\end{array}$ \\
\hline $\begin{array}{l}\text { Peer review } \\
\text { An assessment by a peer, (“a } \\
\text { person of the same age, status, } \\
\text { or ability as another specified } \\
\text { person.", the Oxford Dictionary) }\end{array}$ & $\begin{array}{l}\text { Open or anonymous review from a person of the } \\
\text { same age, status, or ability as another specified } \\
\text { person considering various dimensions inlc. Professional } \\
\text { performance, compliance with strategy, personal } \\
\text { traits etc. }\end{array}$ \\
\hline
\end{tabular}

\section{Catastrophic perioperative complications}

We define catastrophic perioperative complications as consequential, unexpected, unplanned events that should not happen or have happened, and that are or were potentially preventable. When they do happen, they can affect patients, peers, equipment, clinical infrastructure, leadership, and departmental strategy, i.e., for example, being the best performing department with the fewest complications. Catastrophic perioperative complications have myriad causes.

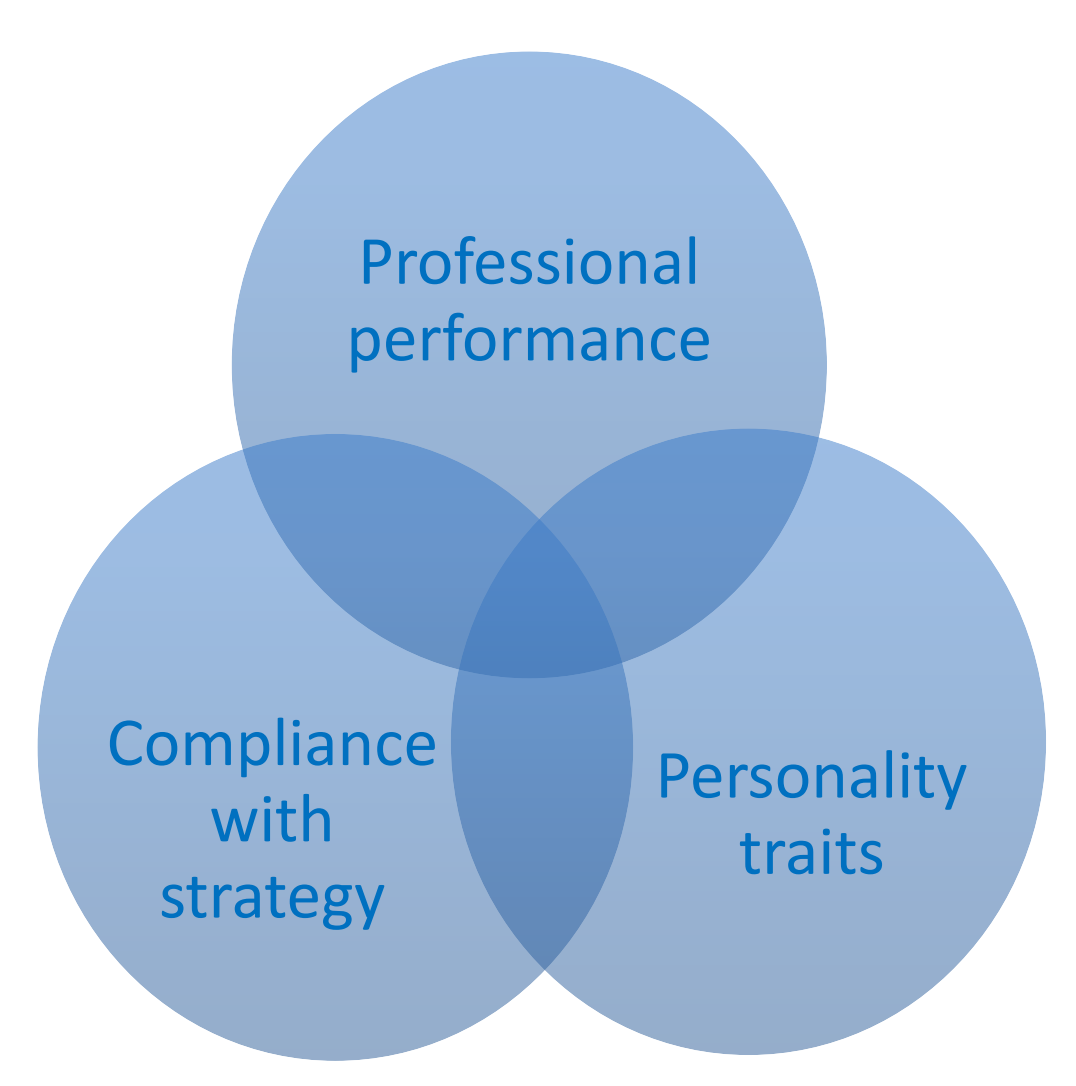

Dimensions to be included

Professional performance, compliance with department's strategy and personality in acute care peer review to prevent, manage, and learn from catastrophic complications. All can be benchmarked with departmental mission, vision, and values, defined in the strategy.

\section{Methods}

We searched PubMed, Embase and EBSCO, Web of Science, JSTOR and WISO and reviewed current evidence considering peer review, i.e. the performance assessment by someone of the same status and ability, from both management science and medicine to define, build, and adjust a department's mission, vision, and culture.

\section{Results}

While respective evidence is sparse in medicine, such deriving from management sciences is overwhelming and suggests peer review being integrated in every department's mission and vision to evolve from a peer review-adverse culture towards an open and supportive environment since not only the fear of performance review, but also the lack of it generate dysfunctional work environments. Further, professional performance, compliance with departmental strategy, and personality traits can be addressed preventively, retrospectively, and acutely, and can be benchmarked with the departmental mission, vision, and values, defined in the strategy.

\section{Catastrophic perioperative complication}

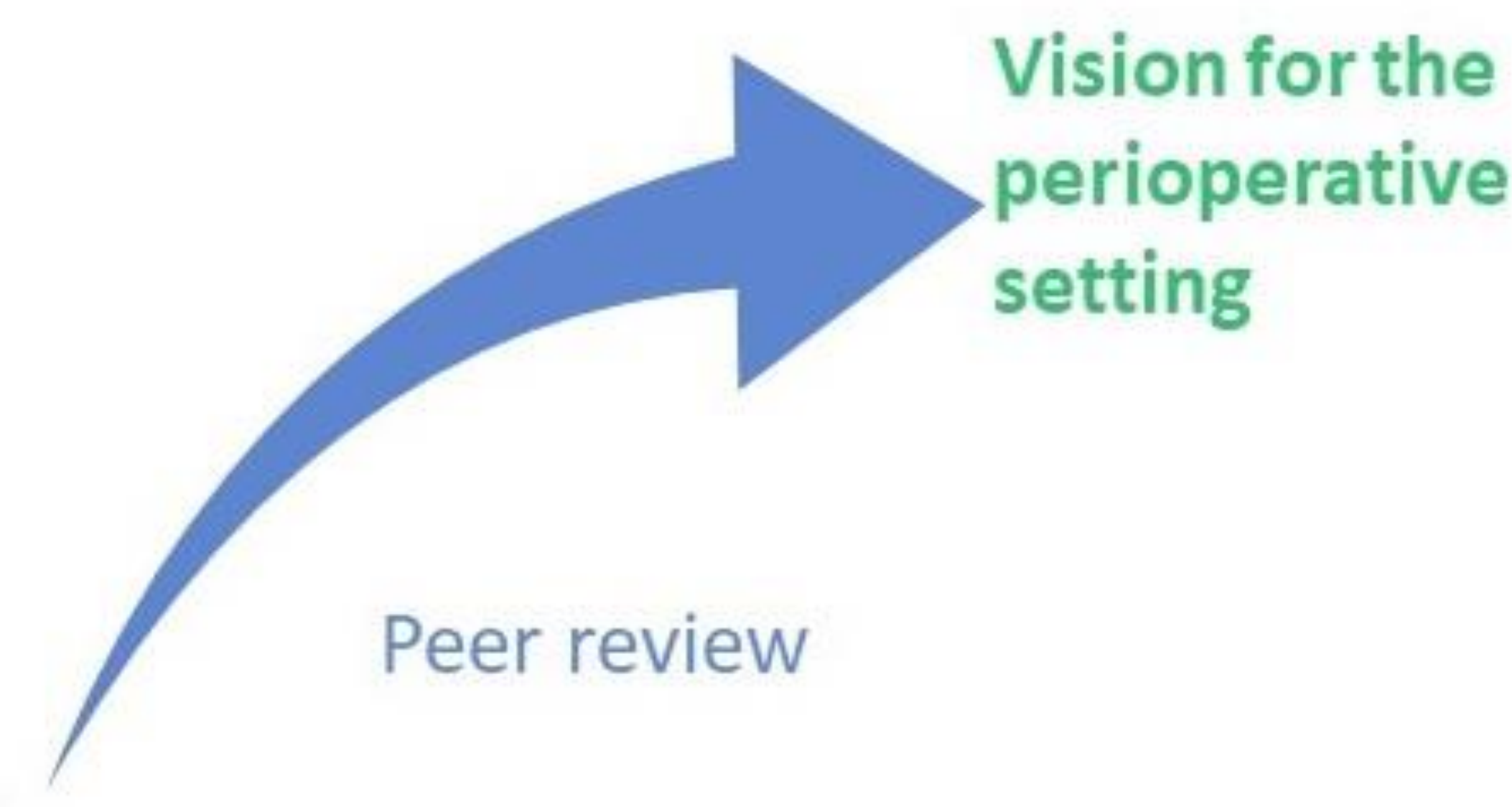

Mission in the perioperative setting

\section{Conclusion}

Conclusions: Aiming at reducing perioperative morbidity and mortality, peer review provides a valuable leadership tool to improve in the face of ever increasing complex workplace settings and a key element towards preventing, managing, and learning from catastrophic perioperative complications. Both leadership and peers in perioperative medicine have to be aware that change is not an event but rather a process that requires time, has to follow specific steps, and has to be planned strategically.

\section{Long term perspective}

Peer review might be a key element in preventing, dealing with and learning from catastrophic perioperative complications. With a well defined peer review system in place, both individuals and departments involved in perioperative medicine benefit from an additional strategy to improve their effort in preventing, dealing with and learning from catastrophic events.

\section{References and suggested readings}

Loup $O$ and Luedi MM. Peer review in perioperative medicine. In: "Catastrophic Perioperative Complications and Management - A Comprehensive Textbook" Eds.: Fox CJ, Ghali GE, and Cornett EM Cambridge University Press. 2018 [In Press]

2 Cantillon P and Sargeant, J. Giving feedback in clinical settings. BMJ, 337, 2008 